\title{
Hepatitis D Virus Replication
}

\author{
John M. Taylor \\ Fox Chase Cancer Center, Philadelphia, Pennsylvania 19111 \\ Correspondence: john.taylor@fccc.edu
}

\begin{abstract}
This work reviews specific related aspects of hepatitis delta virus (HDV) reproduction, including virion structure, the RNA genome, the mode of genome replication, the delta antigens, and the assembly of HDV using the envelope proteins of its helper virus, hepatitis $B$ virus (HBV). These topics are considered with perspectives ranging from a history of discovery through to still-unsolved problems. HDV evolution, virus entry, and associated pathogenic potential and treatment of infections are considered in other articles in this collection.
\end{abstract}

$T^{\mathrm{h}}$ he first clue to the existence of hepatitis D virus (HDV) came from studies of patients with a more severe form of hepatitis B virus (HBV) infection (Rizzetto et al. 1977). These patients produced an antibody that interacted with a novel antigen, named delta, present in the nuclei of hepatocytes of liver biopsies from the same patients. These original reports of delta antigen suggested that it might be just an indicator of a more severe form of HBV. However, further study showed that the delta antigen was associated with a separate infectious agent, referred to a "hepatitis delta virus" or HDV, for instance, experimental transmission of infection to chimpanzees, using $\mathrm{HBV}$ as a helper virus (Rizzetto et al. 1980a). Additional proof was obtained by transmission of HDV infection to woodchucks, this time using woodchuck hepatitis virus (WHV) as the helper (Ponzetto et al. 1984).

\section{VIRION STRUCTURE}

It is clear from the above studies that HDV particles make use of the envelope proteins produced by HBV (or WHV in woodchucks). Rate-zonal and equilibrium centrifugation procedures were applied to patient sera to separate HDV from $\mathrm{HBV}$ and the noninfectious subviral particles of HBV, which are made up of HBV envelope proteins. Although HBV is $42 \mathrm{~nm}$ in diameter, these subviral particles are present as $25-\mathrm{nm}$ diameter spheres and 22-nm diameter filaments, which are present in 1000- to 1,000,000-fold excess relative to HBV (Ganem and Schneider 2001). They lack other HBV-encoded proteins, as well as HBV DNA. Relative to HBV, HDV is less dense and of somewhat smaller size, $\sim 39$ nmin diameter (Rizzetto et al. 1980b; He et al. 1989). HDV contains not only the delta antigen but also an RNA genome (Rizzetto et al. 1980b).

Editors: Christoph Seeger and Stephen Locarnin

Additional Perspectives on Hepatitis B and Delta Viruses available at www.perspectivesinmedicine.org

Copyright (C) 2015 Cold Spring Harbor Laboratory Press; all rights reserved; doi: 10.1101/cshperspect.a021568

Cite this article as Cold Spring Harb Perspect Med 2015;5:a021568 
J.M. Taylor

HBV is quite homogenous in size and structure. Detailed structural models of HBV, at the atomic level, were first obtained for the internal nucleocapsid. Later, cryoelectron microscopy reconstructions provided evidence that the complete particle contained $\sim 240$ molecules of the envelope proteins (Seitz et al. 2007). Comparable structural models of HDV are still not available. HDV, produced in cell culture, then affinity-purified and examined by electron microscopy, shows a heterogeneous size, thus complicating structural modeling (Gudima et al. 2007a). Furthermore, although the internal RNA genome is associated with $\sim 70$ copies of the delta antigen (Ryu et al. 1993), there has been no clear evidence for a defined nucleocapsid structure for HDV.

\section{THREE HDV RNAs}

In 1986, three groups reported that the RNA genome of HDV is single-stranded, very small
( $\sim 1700$ nucleotides), and circular in conformation (Chen et al. 1986; Kos et al. 1986; Wang et al. 1986). One of these reports also showed that there are two additional HDV RNAs in infected cells (Chen et al. 1986). One, several-fold less abundant than the circular RNA genome, was its exact complement, referred to as the "antigenome." Nucleotide sequence analysis indicated that the open reading frame (ORF) of the delta antigen was on the antigenome (Wang et al. 1986). Because it seemed unlikely that a circular RNA could be translated, a search was made for a linear mRNA, with the same polarity as the antigenome. This search revealed a $\sim 800 \mathrm{nt}, 3^{\prime}$ polyadenylated RNA (Chen et al. 1986). Later studies showed that the 800 nt RNA was capped and had a unique $5^{\prime}$-end (Hsieh et al. 1990; Gudima et al. 2000). Creation of the polyadenylated 3 -end of the RNA was determined to be dependent on a nearby AAUAAA signal and a CA acceptor site, which are typical for $\operatorname{poly}(\mathrm{A})$ processing of host mRNAs (Hsieh et al. 1990).

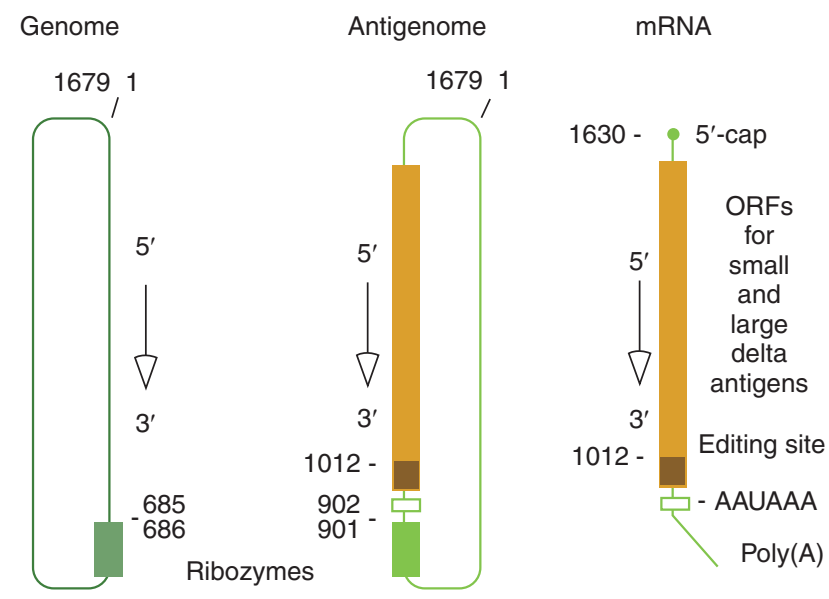

Figure 1. Three HDV RNAs that accumulate during replication. The numbering of nucleotides refers to the 1679 genomes sequenced by Kuo et al. (1988b). The circular RNA genome and its exact complement, the antigenome, are drawn as unbranched rod-like structures. Both of these RNAs contain a small domain, indicated by a solid green box, which, after appropriate folding, will act as an efficient self-cleaving ribozyme. The antigenome contains a region, indicated by a solid brown box, that contains the open reading frames (ORFs) for the small and large delta antigens. However, these proteins are translated from a shorter linear RNA. This third RNA contains a $5^{\prime}$-cap structure and in part, because of an AAUAAA polyadenylation signal indicated by a small open green box, is $3^{\prime}$-polyadenylated. The ORF of the small delta antigen is increased to that of the large delta antigen, by a posttranscriptional RNA editing event that occurs at position 1014 of the antigenome, corresponding to the middle of an UAG amber termination codon, thereby allowing an extended translation via a UGG codon for tryptophan. In the liver of an infected animal, the abundances of these three RNAs per average cell are $\sim 300,000$, 50,000, and 600 (Chen et al. 1986). 
HDV Replication

The three RNAs are represented in Figure 1. The per-cell abundances of genome, antigenome, and mRNA in infected liver tissues were estimated at $\sim 300,000,60,000$, and 600 copies, respectively.

In addition to being circular, nucleotide sequence analysis showed that the HDV genome had the potential to fold on itself via base pairing to form an unbranched rod-like structure (Fig. 1) (Wang et al. 1986). This suggestion was confirmed by electron microscopy (Kos et al. 1986). The extent of base pairing is predicted to be $\sim 74 \%$ (Kuo et al. 1988b). The significance of this much base pairing, per se, may be misleading, because folding of different random sequences of identical length and base composition revealed many with the same or a larger degree of base pairing (Taylor 2014). However, at least some of the base pairing of HDV genomic (and antigenomic) RNA appears essential. As shown in Figure 1, and discussed further below, both the genome and antigenome contain a domain that can fold into a specific conformation (not the rod-like structure) and act as a selfcleaving ribozyme. A conformation of the antigenomic RNA (a part of the rod-like structure) was also found to act as a substrate for site-specific RNA editing, mutating the stop codon of delta antigen (now called small delta antigen) and thereby allowing the translation of a second, larger form of the delta antigen (Fig. 2).

\section{GENOTYPES}

Since 1986, many isolates of HDV from around the world have been sequenced. This information led to the recognition of three, then four, and, currently, eight different "genotypes" (Radjef et al. 2004; Le Gal et al. 2006). Between genotypes there can be as much as $35 \%$ difference in nucleotide sequence (Deny 2006). These genotypes can show somewhat specific geographic distributions and even association with specific genotypes of HBV (Deny 2006), although the significance of these observations is uncertain. The lengths of different HDV genome sequences fall in a narrow range, from 1672 to 1697 nucleotides (Le Gal et al. 2006; Rocheleau and Pelchat 2006).

\section{ARE HDV RNA CIRCLES UNIQUE?}

No other RNA virus of animals has been found with a genome that is either as small as HDV or of a circular conformation. In contrast, many subviral agents of plants have a circular RNA genome that is even smaller, down to $240 \mathrm{nu}$ cleotides of RNA. These plant subviral agents

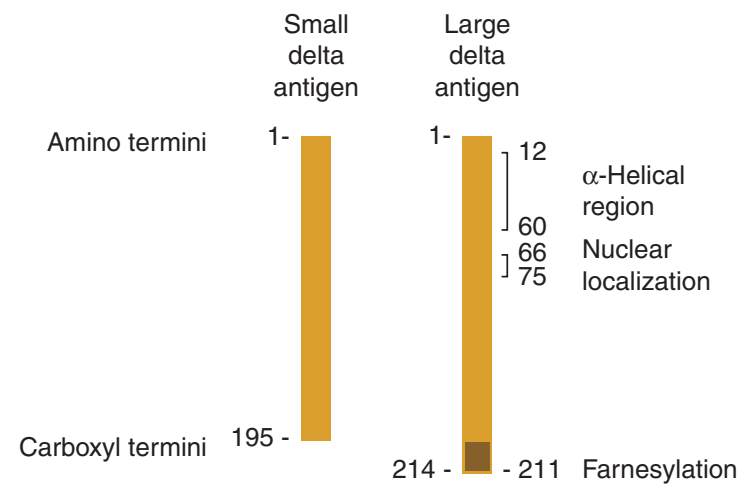

Figure 2. Two forms of the delta antigen. As a consequence of site-specific RNA editing during HDV RNA replication, the coding region for the small delta antigen (195 amino acids [aa]) is increased to allow translation of the large delta antigen (214 aa). The small and large forms are both highly basic proteins and share features, such as a nuclear localization signal and a region with a propensity to form $\alpha$-helices. The unique carboxyl terminus of the large protein contains a cysteine, four amino acids from the terminus, which is the site for a farnesylation that, in turn, is essential for the ability of this protein to facilitate assembly using the envelope proteins of HBV. 
J.M. Taylor

are called "viroids" (Flores et al. 2012). They have no known protein coding capacity. Unlike HDV, viroids do not have helper viruses. Replication thus involves redirection of host proteins. In most cases, viroids are detected because of their association with various forms of plant disease.

"Virusoids" is a term originally applied to another type of subviral agents of plants (Symons and Randles 1999), some of which have small circular RNA genomes. They differ from viroids in requiring a helper virus; some, but not all, encode proteins. The helper virus typically provides RNA-directed RNA polymerase activity to replicate the virusoid genome. (This is in contrast to HDV where the sole function of the helper $\mathrm{HBV}$ is to provide envelope proteins.) The nucleotide sequences of some virusoids show that they were actually derived from their helper virus.

HDV has both similarities and differences relative to plant viroids and virusoids. One of the differences from the viroids is that HDV encodes the delta antigen, which is essential for HDV replication (Fig. 2); however, unlike virusoids, it does not require the helper HBV for replication of its RNA genome. The analogy to viroids has led to models of the origin of HDV via the recombination between a hypothetical human viroid and a host-coding sequence (Brazas and Ganem 1996). It has also led to attempts to apply modified versions of what are called rolling-circle models of viroid replication to the replication of HDV RNA, as represented in Figure 3 and discussed below (Taylor 1990).

For some time, it has been been accepted that the circular conformation of HDV RNA is unique relative to all known viruses of animals. However, several host cell RNAs were found to be circular in conformation. They are considered to result from aberrations in RNA splicing, "miss-splicing" (Nigro et al. 1991). For example, if a splice donor acts on a splice acceptor that is $5^{\prime}$ rather than at the typical $3^{\prime}$ location, an RNA circle of the intervening sequence can be produced. Examples of host RNA circles have greatly increased in the last 3 years; this discovery has been largely the consequence of new and more extensive RNA-sequencing strategies. It is now realized that, in animal cells, many RNA polymerase II RNA transcripts are processed to form RNA circles (Danan et al. 2011; Jeck et al. 2012; Hansen et al. 2013; Memczak et al. 2013). Such RNA circles can even be as abundant as their homologous mRNAs, that is, spliced linear RNAs with a $5^{\prime}$-cap structure and a $3^{\prime}$-polyadenylation. RNA circles can have increased stability, because the majority of host nuclease activity is exo- rather than endonucleolytic. Such examples of host RNA circles may soon be extended to the nonhost RNAs produced during animal virus infections. Thus, it is possible that HDV originated via the selection of an RNA circle generated during chronic HBV infection of the liver (Taylor 2014).

\section{ARE HDV RIBOZYMES UNIQUE?}

As illustrated in Figure 1, both the genome and antigenome of HDV contain a ribozyme domain (Kuo et al. 1988a; Sharmeen et al. 1988). These are related sequences, $<100$ nucleotides in length, which have the ability to fold into specific structures, which leads to site-specific endonucleolytic cleavages, both in vitro and in vivo. The self-cleavage site is located immediately $5^{\prime}$ of each domain, and the products of cleavage have a $5^{\prime}-\mathrm{OH}$ and $2^{\prime}-, 3^{\prime}$-cyclic phosphate. In vitro, the cleavage reaction can be reversed to achieve self-ligation (Sharmeen et al. 1989). However, it should be noted that there is evidence that in vivo ligation might actually involve a host RNA ligase (Reid and Lazinski 2000).

For some time, the HDV ribozymes were considered unique. Other ribozymes have been reported before and since the discovery of the HDV ribozyme, but with quite different sequences and predicted structures. Some are found associated with the previously mentioned viroids and virusoids (Symons 1994; Doudna and Cech 2002). In one study, the HDV ribozyme domains were crystallized and atomic structure determined (Ferre-D'Amare et al. 1998). This structure, in turn, allowed structural searches for HDV-like ribozymes. The first one was found in the intron of a human mRNA precursor (Salehi-Ashtiani et al. 2006). More recently, many such HDV-like ri- 
HDV Replication
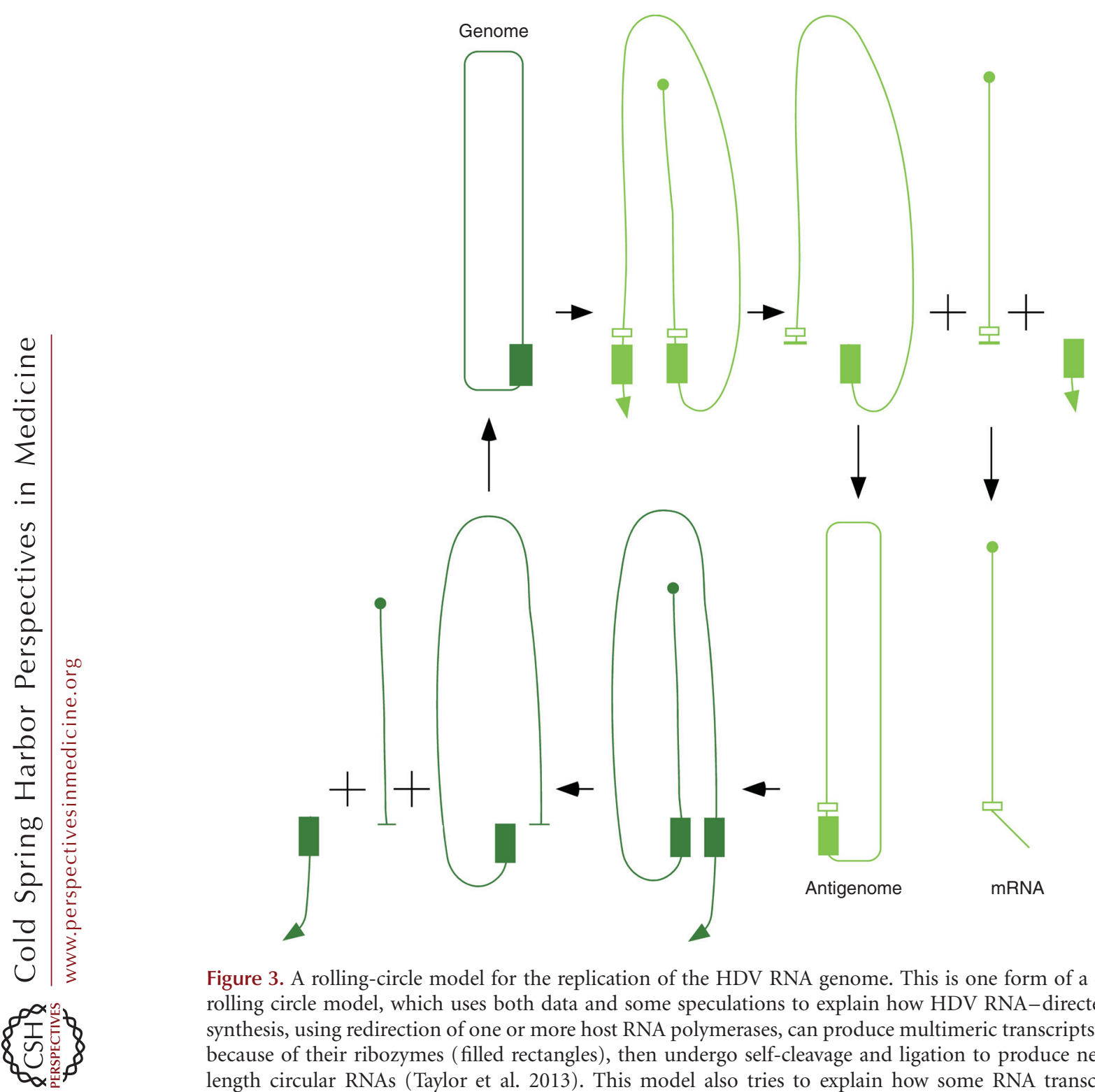

Figure 3. A rolling-circle model for the replication of the HDV RNA genome. This is one form of a doublerolling circle model, which uses both data and some speculations to explain how HDV RNA-directed RNA synthesis, using redirection of one or more host RNA polymerases, can produce multimeric transcripts, which, because of their ribozymes (filled rectangles), then undergo self-cleavage and ligation to produce new unitlength circular RNAs (Taylor et al. 2013). This model also tries to explain how some RNA transcripts of antigenomic polarity can go on to be processed to produce the observed mRNA for the delta antigens. Such a transcript is consistent with data that the $5^{\prime}$-end has a unique location and is capped, and that the $3^{\prime}$-end is polyadenylated as directed by an essential AAUAAA signal (open rectangle).

bozyme structures were identified and, in some cases, shown to be functional (Webb et al. 2009). These structures are now known to be present in RNA, not just of many animal species but also in plants and even on an insect virus. In some situations, they are found in association with sequences of transposable ele- ments. It is suspected that their action might facilitate translation of encoded sequences ( $\mathrm{Ru}-$ minski et al. 2011; Riccitelli and Luptak 2013). Be that as it may, the HDV genomic ribozyme is not associated with translation, and the antigenomic ribozyme is located not $5^{\prime}$ but $3^{\prime}$ of the coding region for the delta antigen and, as 
J.M. Taylor

seen in Figure 1, even $3^{\prime}$ of the polyadenylation signal.

Interestingly, the folding of the genomic and antigenomic RNAs into rod-like structures interferes with the activity of the ribozymes. More specifically, sequences on the opposite side of the rod act as an attenuator, forcing the ribozyme out of its active conformation (Lazinski and Taylor 1995a,b). However, it is not yet known whether the HDV-like ribozymes are in any way regulated in vivo.

\section{TWO DELTA ANTIGENS}

As shown in Figure 2, the delta antigen of virus particles exists in two main forms (Bergmann et al. 1990). The small form was first shown to be essential for the accumulation of HDV RNA species in cells (Kuo et al. 1989). The large form, which has an additional 19 amino acids at the carboxyl terminus, was first found to be a dominant negative inhibitor of replication supported by the small delta antigen (Chao et al. 1990). Later, it was shown to be essential for the assembly of HDV RNA into virus, presumably via interaction with HBV envelope proteins (Chang et al. 1991). A clue to how these two forms of delta antigen arose was when a cDNA clone of HDV was used to transfect cells in culture, as well as the liver of a chimpanzee. The sequence of this cDNA directed translation of the small delta antigen, and yet, as replication proceeded, not only the small form but also increasing amounts of the large form of delta antigen were detected (Sureau et al. 1989). It was soon shown that, during HDV replication, a form of site-specific editing occurred on the HDV RNA to mutate the stop codon of small delta antigen (Luo et al. 1990). Later studies revealed that a host double-stranded RNA-dependent adenosine deaminase, the small form of ADAR1, recognizes a specific structure on the rod-like RNA of antigenomic RNA and converts adenosine to inosine. Replication of this mutated RNA leads to the substitution of guanosine. Thus, on the mRNA, an amber termination codon for the small delta antigen, UAG, is replaced by UGG, the codon for tryptophan (Polson et al. 1996; Wong and Lazinski 2002).
The large and small forms of the delta antigen share much of their primary sequence and, consequently, many associated properties. Both are highly basic proteins (Kuo et al. 1988b). Both proteins have a high level of intrinsic disorder (Alves et al. 2010). This disorder might explain why three laboratories that produced recombinant delta antigen were unable to obtain protein crystals, suitable for X-ray diffraction. Furthermore, the intrinsic disorder may be consistent with the ability of the protein to form multimers and, apparently, associate with many (at least 100) different host proteins (Cao et al. 2009).

Early studies predicted that amino acids $12-60$ of delta antigen could form an $\alpha$-helical structure. This prediction was tested using a synthetic peptide (Rozzelle et al. 1995). The peptide readily formed crystals suitable for Xray diffraction. The deduced structure showed extensive $\alpha$-helicity, along with dimer formation, via an antiparallel coiled-coil (Zuccola et al. 1998). This region has since been referred to as the coiled-coil domain (CCD). There are additional in vivo studies that show that this region is needed for self-dimerization of delta antigen.

The deduced structure of the peptide also indicated that octamers could form. In support of this idea, a fraction of purified molecules of full-length small delta antigen were shown to form octamers in vitro (Zuccola et al. 1998). There is also evidence that octamers will form in vivo using sites located within the region between amino acids 12-60 of delta antigen (Moraleda et al. 2000; Cornillez-Ty and Lazinski 2003).

The need for specific higher order multimers of small delta antigen to support HDV RNA replication was presaged by early studies that showed that relatively small amounts of the large delta antigen, which does not support replication, could act as a dominant negative inhibitor of replication (Chao et al. 1990).

Possible host protein partners of delta antigen include nucleolin (Lee et al. 1998) and another nucleolar protein, B23 (Huang et al. 2001). However, it is unclear whether these observations are caused by direct interaction with 
delta antigen, or occur via a mutual ability to bind RNA. Other delta antigen partners include subunits of DNA-directed RNA polymerase II, supportive of the hypothesis that this enzyme is directly involved in HDV RNA-directed RNA transcription (Cao et al. 2009).

An early study reported two regions on delta antigen, referred to as arginine-rich motifs (ARMs), were essential for RNA binding and support of HDV replication (Lee et al. 1993). These were located between amino acids 97146. Another report asserted that, in vitro, using recombinant protein RNA binding could be achieved that was specific for the HDV rod-like folding (Chao et al. 1991). Both of these reports have recently been called into question. It is now appreciated that the ability of delta antigens to bind nucleic acid is largely controlled by the ability to multimerize (Alves et al. 2010). However, in vitro, such forms with their increased net positive charge bind not only HDV RNAs, genomic and antigenomic, but also to singleand double-stranded non-HDV RNAs and DNAs (Alves et al. 2010). Thus, to date, no study with recombinant, full-length delta antigen has been able to show RNA binding that is clearly specific for HDV rod-like RNA. In contrast, studies using a truncated form of the delta antigen (with removal of 35 carboxy-terminal amino acids), that still multimerizes in vitro predominantly to octamers, showed binding that was somewhat specific for HDV rod-like RNA. This binding required a delta RNA fragment of at least of 311 nucleotides (Defenbaugh et al. 2009). With this in vitro system, it was recently found that the above-mentioned ARMs are not required (Daigh et al. 2013). This supports a model in which a multimer of the delta antigen provides numerous sites at which contact is made with the HDV rod-like RNA.

As mentioned at the outset, HDV was discovered, in part, because of the detection of the delta antigen in hepatocyte nuclei (Rizzetto et al. 1977). When the delta antigens are expressed in the absence of HDV replication, they also localize to the nucleus. Early studies defined two or even three regions on the delta antigens, spanning amino acids 35-89, that were essential for nuclear localization (Chang et al.
1992). A later study using fusion proteins as a reporter has asserted that only one of these regions, amino acids 66-75, is essential (Alves et al. 2008).

Various posttranslational modifications have been detected on both forms of the delta antigen. Phosphorylation is present and mainly on the large form (Bichko et al. 1997; Mu et al. 2001). There are also modifications via methylation ( $\mathrm{Li}$ et al. 2004), acetylation ( $\mathrm{Mu}$ et al. 2004), and sumoylation (Tseng et al. 2010). It is still unclear which, if any, of these modifications are essential for intracellular delta protein localization and/or functionality. This is in contrast to modification that is unique to the large delta antigen and is essential. It is a farnesylation at a unique cysteine site, the fourth amino acid from the novel carboxyl terminus. This site was first predicted to be a site for isoprenylation (a term that includes farnesylation and geranylgeranyl modifications) (Glenn et al. 1992), which was confirmed experimentally, and finally shown to involve farnesylation (Otto and Casey 1996). The three amino-terminal amino acids are removed in this farnesylation process (Farh et al. 1995). This farnesylation may contribute to the ability of the large delta antigen to inhibit replication supported by the small delta antigen (Hwang and Lai 1994). As will be explained below, this modification also has a role in virus assembly (Hwang and Lai 1993).

It has been known since 1977 that the delta antigens are located predominantly in the nucleus of infected cells (Rizzetto et al. 1977). Subnuclear localization sites include the nucleolus, especially when the delta antigens are expressed in the absence of replicating HDV RNA (Han et al. 2009). However, once replication is underway, the antigen is more likely to be in the nucleoplasm, just as for RNA polymerase II, which is needed for HDV RNA replication (Han et al. 2009). And, as replication proceeds with increasing levels of the large delta antigen, the intracellular distribution changes to include cytoplasmic localization (Bichko and Taylor 1996). It has been reported that a unique region of large delta antigen, at amino acids 198-210, contains a nucleolar export signal (Lee et al. 2001). 
J.M. Taylor

\section{MODE OF RNA REPLICATION}

As mentioned above, and reviewed elsewhere (Taylor 1999; Flores et al. 2012), the similarities of HDV genomic and antigenomic RNAs to those of certain plant viroids has led to the idea that rolling-circle models for viroid replication also explain HDV RNA replication. Figure 3 is an example of such a model, one referred to as a "double rolling circle," because both genomic and antigenomic RNAs are considered as circular templates. In the model, ribozymes cleave multimeric transcripts to what is considered "unit length" species, which, in turn, undergo self-ligation to form circles. Although protein-free self-ligation is possible (Sharmeen et al. 1989), one report suggests that a host ligase is required (Reid and Lazinski 2000).

In the model in Figure 3, there has to be a mechanism for synthesis of a third HDV RNA, the delta antigen mRNA. This species has a unique $5^{\prime}$-end, indicating a specific site for the initiation of transcription. And the RNA undergoes posttranscription RNA processing to add a $5^{\prime}$-cap and $3^{\prime}$-polyadenylation, very much like that found for host RNA polymerase II transcripts that are processed to become mRNAs.

There is good evidence that transcription of HDV RNAs requires the host RNA polymerase II (Chang et al. 2008). There are more controversial data that a second host polymerase is also needed during transcription from antigenomic RNA to produce new genomic RNA (Modahl et al. 2000; Tseng and Lai 2009). And there are in vitro data that the small delta antigen might be a facilitator of the transcription of delta RNA by RNA polymerase II (Yamaguchi et al. 2001, 2007). There is also evidence that not just purified polymerase II but also RNA polymerases I and III will bind in vitro to HDV-related RNA fragments (Greco-Stewart and Pelchat 2010). In summary, there has yet to be convincing reconstitution, in vitro, of transcription on fulllength HDV RNAs and the definition of what might be called promoter elements.

An important confirmation of the essential role of the small delta antigen in RNA accumulation was achieved by transfection into cells of linear HDV RNAs, transcribed in vitro; this only led to RNA replication when the recipient cells already expressed the small delta antigen (Glenn et al. 1990). In other model systems, it has been shown that the extent to which cells can accumulate HDV RNA species is directly proportional to the amount of small delta antigen (Chang et al. 2005a).

The variety of experimental methods that lead to initiation of HDV replication is quite amazing. For example, cells can be transfected with a pair of linear RNAs, each less than fulllength but together containing, in sum, all of the HDV sequences, and, in the presence of delta antigen, this leads to HDV replication (Gudima et al. 2005). Again, cells can be transfected using linear HDV RNAs that contain inserts of up to 1000 nucleotides of non-HDV sequence, and yet replication of HDV is achieved, along with removal of the inserted sequences (Gudima et al. 2006). Finally, cells can be transfected with linear RNAs that are up to two nucleotides shorter than full length, and replication is initiated with random sequences somehow being added to fill in the missing sequences (Chang and Taylor 2002).

A question has been whether recombination occurs between HDV genomes. Data have been reported, both in transfected cells and in patients, as evidence for recombination between two different HDV genotypes (Wu et al. 1999; Chao et al. 2006).

\section{POSTTRANSCRIPTIONAL RNA EDITING}

Early studies of delta antigen proteins associated with HDV showed that there are two sizes of the protein. From nucleotide sequencing, it could be seen that there are microheterogeneities in the RNA sequence (Wang et al. 1986). Further, two proteins could be translated from overlapping ORFs; the amino termini were the same, but the carboxyl termini were determined by whether an amber termination codon, the predicted carboxyl terminus of the small delta antigen, was present or not. When a cDNA clone corresponding to just one sequence, the one with the amber codon, was transfected into cells or used to transfect the liver of a chimpanzee, HDV genome replication was initiated (Sureau 
et al. 1989). However, in contrast to expectations, both proteins were then produced during HDV replication. Furthermore, when the replicating RNA was sequenced, it was found that, as a function of time after the initiation of replication, an increasing fraction of the RNAs (up to $\sim 40 \%$ ) contained a change of the amber termination UAG codon to UGG, the codon for tryptophan. Subsequent studies revealed that this change was performed by a form of a host enzyme, double-stranded RNA-activated adenosine deaminase, the small form of ADAR1 (Polson et al. 1996; Wong and Lazinski 2002). This editing site was on the antigenome of HDV (not the mRNA itself), and it was defined by a partially double-stranded region on this RNA, as defined by the site itself in base pairing with sequences from the opposite side of the predicted rod-like folding. The delta antigen, which is an RNA-binding protein, was later shown as a negative regulator of this editing (Polson et al. 1998).

Separate studies found that the small antigen was essential for HDV RNA accumulation. In contrast, the large form was an inhibitor of accumulation. In fact, it is a dominant-negative inhibitor; that is, it can efficiently reduce the ability of the small form to support the accumulation of processed RNA transcripts. And yet, as discussed in other sections, the large delta antigen is essential for the assembly process that makes use of the HBV envelope proteins. It is, therefore, believed that the accumulation of edited genomes, along with the accumulation of larger delta antigen, regulates the extent of HDV RNA synthesis and accumulation.

The editing process raises some interesting issues. It means that edited genomes, although leading to synthesis of the inhibitory large delta antigen, should be packaged. And this occurs. But such virions would not be able to initiate HDV replication because they do not encode the essential small delta antigen. Thus, a fraction of HDV particles must be noninfectious for just this reason. A second issue is whether other sites exist on the HDV genome and antigenome that are edited by ADAR1. Studies of long-term HDV replication, as initiated by a single sequence, support the idea that many changes arise via such ADAR1 editing (Chang et al. 2005b). However, there are other changes that occur, which leads to the speculation that these are via another posttranscriptional editing processes and/or that many of the nucleotide changes are a consequence of misincorporation during rounds of RNA-directed RNA synthesis. Whatever the case, nucleotide changes could account for some of the observed genotypes of HDV, which, as mentioned earlier, differ by as much as $35 \%$ in nucleotide sequence.

\section{VIRUS ASSEMBLY}

As mentioned above, the large form of the delta antigen, with its 19 carboxy-terminal amino acids relative to the small delta antigen, is essential for virion assembly. A part of this essential nature is linked to the carboxy-terminal farnesylation (Hwang and Lai 1994), but there are data that other features of the carboxyl terminus extension are also important for virus assembly (Lee et al. 1994; Moraleda et al. 1999).

Some important host and viral proteins undergo farnesylation (Laezza et al. 1998). For this reason, inhibitors of farnesylation have been developed and tested in humans (Sebti and Hamilton 2000). Experimental studies have shown that these inhibitors, when applied to chimeric mice carrying human hepatocytes infected with HBV and HDV, inhibit HDV assembly (Bordier et al. 2002, 2003). Thus, proof of principle has been shown for potential HDV antiviral therapy via farnesylation inhibitors.

For reasons not yet fully understood, only the genome and not the complementary antigenome is assembled into HDV. A proposed mechanism is that, although both genomic and antigenomic RNA replication takes place in the nucleus, there is selective export of genomic RNA to the cytoplasm. However, achieving specificity for virion assembly might be more complicated than this. For HDV and other negativestranded viruses, such specificity continues to be a topic for research and speculation (Green et al. 2014).

As presented in more detail in the literature, $\mathrm{HBV}$ replication produces three related forms of envelope protein, referred to as the large, mid- 
J.M. Taylor

dle, and small surface antigens, or simply, L, M, and $\mathrm{S}$. $\mathrm{L}$ and $\mathrm{M}$ share the same carboxyl terminus as S. L has an amino-terminal domain referred to as preS1 that is unique relative to M. Similarly, $\mathrm{M}$ has a unique amino-terminal domain relative to $\mathrm{S}$, which is called preS2. Assembly of the HBV nucleocapsid using these three envelope proteins is complex and highly inefficient. The HBV nucleocapsid only goes into particles that contain the $\mathrm{L}$ protein together with the smaller proteins. For each 42-nm diameter HBV released, there may be released as many as 1,000,000 empty subviral particles (SVPs). These SVPs exist in two main forms, small 25-nm diameter spheres and rod-like particles of $22 \mathrm{~nm}$ diameter, and of variable length (Patient et al. 2007).

Unlike HBV, HDV assembly does not require the L protein (Gudima et al. 2007b; Patient et al. 2007). Thus, HDVassembly can exploit the inefficiency of HBV assembly. However, only those particles that do contain L protein are infectious (Sureau et al. 1993).

This conclusion has recently been extended to show that both HBV and HDV both bind to the newly discovered primary host receptor via the same unique domain in the preS1 region of the L protein (Yan et al. 2012). This being said, it is not yet clear how many copies of the L protein are needed per particle, and whether this requirement is the same for both HBV and HDV. Unquestionably, the breakthrough of receptor identification has made possible new waves of HBV and HDV research.

Because HDV assembly requires the envelope proteins of $\mathrm{HBV}$, it has been sometimes assumed that, in natural infections, HDV must enter hepatocytes already infected with HBV. However, experimental studies indicate that this is not always true. There is experimental evidence that even 6 weeks after HDV infection in the absence of HBV, superinfection with HBV can lead to assembly of new HDV particles (Giersch et al. 2014).

Controversy remains as to whether HDV replication and/or assembly modulates, or modulates in a significant way, the replication and/or assembly of HBV. To date, no direct effect on HBV has been found. Indirectly, cyto- kines produced during the immune response to HDV infection of HBV carriers can lead to temporary suppression of HBV replication (Taylor et al. 2013).

\section{CONCLUDING REMARKS}

As cited in this review, significant unresolved questions and controversies regarding HDV and its replication remain to be studied. A key issue is the origin of HDV itself. At one time, the similarities between HDV and the plant viroids (Branch et al. 1990) led to the idea that HDV arose from some recombination between a hypothetical human viroid and a host gene (Brazas and Ganem 1996). One study, which has not so far been repeated, even asserted that a modified form of HDV would replicate in plants (Taylor and Pelchat 2010). However, recent findings of abundant host RNAs that can be processed to circular forms have led to the hypothesis that HDV and the plant viroids, of which there are many different species, represent examples of convergent evolution. That is, they represent a class of small circular RNAs that have been selected because of an ability to be replicated by host genes. They may have even arisen from what were initially helper viruses. For example, HDV may have arisen from RNA circles produced from HBV RNAs during chronic HBV infections (Taylor 2014).

\section{ACKNOWLEDGMENTS}

William Mason provided many valuable comments on this manuscript.

\section{REFERENCES}

Alves C, Freitas N, Cunha C. 2008. Characterization of the nuclear localization signal of the hepatitis delta virus antigen. Virology 370: 12-21.

Alves C, Cheng H, Roder H, Taylor J. 2010. Intrinsic disorder and oligomerization of the hepatitis delta virus antigen. Virology 407: 333-340.

Bergmann KF, Cote PJ, Gerin JL. 1990. Immunological characterization of hepatitis delta antigen. In Progress in clinical and biological research (ed. Gerin JL, Purcell RH Rizetto M), pp. 165-171. Wiley, New York. 
Bichko VV, Taylor JM. 1996. Redistribution of the delta antigens in cells replicating the genome of hepatitis delta virus. J Virol 70: 8064-8070.

Bichko V, Barik S, Taylor J. 1997. Phosphorylation of the hepatitis delta virus antigens. J Virol 71: 512-518.

Bordier BB, Marion PL, Ohashi K, Kay MA, Greenberg HB, Casey JL, Glenn JS. 2002. A prenylation inhibitor prevents production of infectious hepatitis delta virus particles. J Virol 76: 10465-10472.

Bordier BB, Ohkanda J, Liu P, Lee SY, Salazar FH, Marion PL, Ohashi K, Meuse L, Kay MA, Casey JL, et al. 2003. In vivo antiviral efficacy of prenylation inhibitors against hepatitis delta virus. J Clin Invest 112: 407-414

Branch AD, Levine BJ, Robertson HD. 1990. The brotherhood of circular RNA pathogens: Viroids, circular satellites, and the delta agent. Sem Virol 1: 143-152.

Brazas R, Ganem D. 1996. A cellular homolog of hepatitis delta antigen: Implications for viral replication and evolution. Science 274: 90-94.

Cao D, Haussecker D, Huang Y, Kay MA. 2009. Combined proteomic-RNAi screen for host factors involved in human hepatitis delta virus replication. RNA 15: 19711979.

Chang J, Taylor J. 2002. In vivo RNA-directed, transcription, with template, switching, by a mammalian RNA, polymerase. EMBO J 21: 157-164.

Chang FL, Chen PJ, Tu SJ, Chiu MN, Wang CJ, Chen DS 1991. The large form of hepatitis delta antigen is crucial for the assembly of hepatitis delta virus. Proc Natl Acad Sci 88: 8490-8494.

Chang M-F, Chang SC, Chang C-I, Wu K, Kang H-Y. 1992. Nuclear localization signals, but not putative leucine zipper motifs, are essential for nuclear transport of hepatitis delta antigen. J Virol 66: 6019-6027.

Chang J, Gudima SO, Tarn C, Nie X, Taylor JM. 2005a. Development of a novel system to study hepatitis delta virus genome replication. J Virol 79: 8182-8188.

Chang J, Gudima SO, Taylor JM. 2005b. Evolution of hepatitis delta virus RNA genome following long-term replication in cell culture. J Virol 79: 13310-13316.

Chang J, Nie X, Chang HE, Han Z, Taylor J. 2008. Transcription of hepatitis delta virus RNA by RNA polymerase II. Virol 82: 1118-1127.

Chao M, Hsieh S-Y, Taylor J. 1990. Role of two forms of the hepatitis delta virus antigen: Evidence for a mechanism of self-limiting genome replication. J Virol 64: 5066-5069.

Chao M, Hsieh S-Y, Taylor J. 1991. The antigen of hepatitis delta virus: Examination of in vitro RNA-binding specificity. J Virol 65: 4057-4062.

Chao M, Wang TC, Lee SE. 2006. Detection of hepatitis delta virus recombinants in cultured cells co-transfected with cloned genotypes I and IIb DNA sequences. J Virol Methods 137: 252-258.

Chen P-J, Kalpana G, Goldberg J, Mason W, Werner B, Gerin J, Taylor J. 1986. Structure and replication of the genome of hepatitis delta virus. Proc Natl Acad Sci 83: 8774-8778.

Cornillez-Ty CT, Lazinski DW. 2003. Determination of the multimerization state of the hepatitis delta virus antigens in vivo. J Virol 77: 10314-10326.

Daigh LH, Griffin BL, Soroush A, Mamedov MR, Casey JL. 2013. Arginine-rich motifs are not required for hepatitis delta virus RNA binding activity of the hepatitis delta antigen. J Virol 87: 8665-8674.

Danan M, Schwartz S, Edelheit S, Sorek R. 2011. Transcriptome-wide discovery of circular RNAs in Archaea. Nucleic Acids Res 40: 3131-3142.

Defenbaugh DA, Johnson M, Chen R, Zheng YY, Casey JL. 2009. Hepatitis delta antigen requires a minimum length of the hepatitis delta virus unbranched rod RNA structure for binding. J Virol 83: 4548-4556.

Deny P. 2006. Hepatitis delta virus genetic variability: From genotypes I, II, III to eight major clades. In Hepatitis delta virus (ed. Casey JL), pp. 151-171. Springer, Berlin.

Doudna JA, Cech TR. 2002. The chemical repertoire of natural ribozymes. Nature 418: 222-228.

Farh L, Mitchell DA, Deschenes RJ. 1995. Farnesylation and proteolysis are sequential, but distinct steps in the CaaX box modification pathway. Arch Biochem Biophys 318: $113-121$.

Ferre-D’Amare AR, Zhou K, Doudna JA. 1998. Crystal structure of a hepatitis delta virus ribozyme. Nature 395: $567-574$.

Flores R, Ruiz-Ruiz S, Serra P. 2012. Viroids and hepatitis delta virus. Semin Liver Dis 32: 201-210.

Ganem D, Schneider RJ. 2001. Hepadnaviridae: The viruses and their replication. In Fields virology (ed. Knipe DM, Howley PM, Griffin DE, Lamb RA, Martin MA, Roizman B, Straus SE), pp. 2923-2969. Lippincott Williams \& Wilkins, Philadelphia.

Giersch K, Helbig M, Volz T, Allweiss L, Mancke LV, Lohse AW, Polywka S, Pollok JM, Petersen J, Taylor J, et al. 2014. Persistent hepatitis D virus mono-infection in humanized mice is efficiently converted by hepatitis B virus to a productive co-infection. J Hepatol 60: 538-544.

Glenn JS, Taylor JM, White JM. 1990. In vitro-synthesized hepatitis delta virus RNA initiates genome replication in cultured cells. J Virol 64: 3104-3107.

Glenn JS, Watson JA, Havel CM, White JO. 1992. Identification of a prenylation site in the delta virus large antigen. Science 256: 1331-1333.

Greco-Stewart VS, Pelchat M. 2010. Interaction of host cellular proteins with components of the hepatitis delta virus. Viruses 2: 189-212.

Green TJ, Cox R, Tsao J, Rowse M, Qiu S, Luo M. 2014. Common mechanism for RNA encapsidation by negative-strand RNA viruses. J Virol 88: 3766-3775.

Gudima S, Wu S-Y, Chiang C-M, Moraleda G, Taylor J. 2000. Origin of the hepatitis delta virus mRNA. J Virol 74: 7204-7210.

Gudima SO, Chang J, Taylor JM. 2005. Reconstitution in cultured cells of replicating HDV RNA from pairs of less than full-length RNAs. RNA 11: 90-98.

Gudima SO, Chang J, Taylor JM. 2006. Restoration in vivo of defective hepatitis delta virus RNA genomes. RNA 12: 1061-1073.

Gudima S, He Y, Meier A, Chang J, Chen R, Jarnik M, Nicolas E, Bruss V, Taylor J. 2007a. Assembly of hepatitis delta virus: Particle characterization, including the ability to infect primary human hepatocytes. J Virol 81: $3608-$ 3617.

Gudima S, Meier A, Dunbrack R, Taylor J, Bruss V. 2007b. Two potentially important elements of the hepatitis $B$ 
J.M. Taylor

virus large envelope protein are dispensable for the infectivity of hepatitis delta virus. J Virol 81: 4343-4347.

Han Z, Alves C, Gudima S, Taylor J. 2009. Intracellular localization of hepatitis delta virus proteins in the presence and absence of viral RNA accumulation. J Virol 83: 6457-6463.

Hansen TB, Kjems J, Damgaard CK. 2013. Circular RNA and miR-7 in cancer. Cancer Res 73: 5609-5612.

He LF, Ford E, Purcell RH, London WT, Phillips J, Gerin JL. 1989. The size of the hepatitis delta agent. J Med Virol 27: $31-33$

Hsieh S-Y, Chao M, Coates L, Taylor J. 1990. Hepatitis delta virus genome replication: A polyadenylated mRNA for delta antigen. J Virol 64: 3192-3198.

Huang WH, Yung BY, Syu WJ, Lee YH. 2001. The nucleolar phosphoprotein B23 interacts with hepatitis delta antigens and modulates the hepatitis delta virus RNA replication. J Biol Chem 276: 25166-25175.

Hwang SB, Lai MM. 1993. Isoprenylation mediates direct protein-protein interactions between hepatitis large delta antigen and hepatitis B virus surface antigen. J Virol 67: 7659-7662.

Hwang SB, Lai MM. 1994. Isoprenylation masks a conformational epitope and enhances trans-dominant inhibitory function of the large hepatitis delta antigen. J Virol 68: $2958-2964$.

Jeck WR, Sorrentino JA, Wang K, Slevin MK, Burd CE, Liu J, Marzluff WF, Sharpless NE. 2012. Circular RNAs are abundant, conserved, and associated with ALU repeats. RNA 19: 141-157.

Kos A, Dijkema R, Arnberg AC, van der Meide PH, Schellekens H. 1986. The hepatitis delta $(\delta)$ virus possesses a circular RNA. Nature 323: 558-560.

Kuo MY, Sharmeen L, Dinter-Gottlieb G, Taylor J. 1988a. Characterization of self-cleaving RNA sequences on the genome and antigenome of human hepatitis delta virus. J Virol 62: 4439-4444.

Kuo MY-P, Goldberg J, Coates L, Mason W, Gerin J, Taylor J. 1988b. Molecular cloning of hepatitis delta virus RNA from an infected woodchuck liver: Sequence, structure, and applications. J Virol 62: 1855-1861.

Kuo MY-P, Chao M, Taylor J. 1989. Initiation of replication of the human hepatitis delta virus genome from cloned DNA: Role of delta antigen. J Virol 63: 1945-1950.

Laezza C, Di Marzo V, Bifulco M. 1998. v-K-ras leads to preferential farnesylation of $\mathrm{p} 21^{\text {ras }}$ in FRTL-5 cells: Multiple interference with the isoprenoid pathway. Proc Natl Acad Sci 95: 13646-13651.

Lazinski DW, Taylor JM. 1995a. Intracellular cleavage and ligation of hepatitis delta virus genomic RNA: Regulation of ribozyme activity by cis-acting sequences and host factors. J Virol 69: 1190-1200.

Lazinski DW, Taylor JM. 1995b. Regulation of the hepatitis delta virus ribozymes: To cleave or not to cleave? RNA 1: 225-233.

Lee CZ, Lin JH, Chao M, McKnight K, Lai MM. 1993. RNAbinding activity of hepatitis delta antigen involves two arginine-rich motifs and is required for hepatitis delta virus RNA replication. J Virol 67: 2221-2227.
Lee C-Z, Chen P-J, Lai M, Chen D-S. 1994. Isoprenylation of large hepatitis delta antigen is necessary but not sufficient for hepatitis delta virus assembly. Virology 199: 169-175.

Lee CH, Chang SC, Chen CJ, Chang MF. 1998. The nucleolin binding activity of hepatitis delta antigen is associated with nucleolus targeting. J Biol Chem 273: 7650-7656.

Lee CH, Chang SC, Wu CH, Chang MF. 2001. A novel chromosome region maintenance 1 -independent nuclear export signal of the large form of hepatitis delta antigen that is required for the viral assembly. J Biol Chem 276: 81428148.

Le Gal F, Gault E, Ripault MP, Serpaggi J, Trinchet JC, Gordien E, Deny P. 2006. Eighth major clade for hepatitis delta virus. Emerg Infect Dis 12: 1447-1450.

Li YJ, Stallcup MR, Lai MM. 2004. Hepatitis delta virus antigen is methylated at arginine residues, and methylation regulates subcellular localization and RNA replication. J Virol 78: 13325-13334.

Luo G, Chao M, Hsieh S-Y, Sureau C, Nishikura K, Taylor J. 1990. A specific base transition occurs on replicating hepatitis delta virus RNA. J Virol 64: 1021-1027.

Memczak S, Jens M, Elefsinioti A, Torti F, Krueger J, Rybak A, Maier L, Mackowiak SD, Gregersen LH, Munschauer M, et al. 2013. Circular RNAs are a large class of animal RNAs with regulatory potency. Nature 495: 333-338.

Modahl LE, Macnaughton TB, Zhu N, Johnson DL, Lai MMC. 2000. RNA-dependent replication and transcription of hepatitis delta virus RNA involve distinct cellular RNA polymerases. Mol Cell Biol 20: 6030-6039.

Moraleda G, Seeholzer S, Bichko V, Dunbrack R, Otto J, Taylor J. 1999. Unique properties of the large antigen of hepatitis delta virus. J Virol 73: 7147-7152.

Moraleda G, Dingle K, Biswas P, Chang J, Zuccola H, Hogle J, Taylor J. 2000. Interactions between hepatitis delta virus proteins. J Virol 74: 5509-5515.

Mu JJ, Chen DS, Chen PJ. 2001. The conserved serine 177 in the delta antigen of hepatitis delta virus is one putative phosphorylation site and is required for efficient viral RNA replication. J Virol 75: 9087-9095.

Mu JJ, Tsay YG, Juan LJ, Fu TF, Huang WH, Chen DS, Chen PJ. 2004. The small delta antigen of hepatitis delta virus is an acetylated protein and acetylation of lysine 72 may influence its cellular localization and viral RNA synthesis. Virology 319: 60-70.

Nigro J, Cho K, Fearon E, Kern S, Ruppert J, Oliner J, Kinzler K, Vogelstein B. 1991. Scrambled exons. Cell 64: 607613.

Otto JC, Casey PJ. 1996. The hepatitis delta virus large antigen is farnesylated both in vitro and in animal cells. $J$ Biol Chem 271: 4569-4572.

Patient R, Hourioux C, Sizaret P-Y, Trassard S, Sureau C, Roingeard P. 2007. Hepatitis B virus subviral envelope particle morphogenesis and intracellular trafficking. $J$ Virol 81: 3842-3851.

Polson AG, Bass BL, Casey JL. 1996. RNA editing of hepatitis delta virus antigenome by dsRNA-adenosine deaminase. Nature 380: 454-456.

Polson AG, Ley HL III, Bass BL, Casey JL. 1998. Hepatitis delta virus RNA editing is highly specific for the amber/ $\mathrm{W}$ site and is suppressed by the delta antigen. Mol Cell Biol 18: 1919-1926. 
Ponzetto A, Cote PJ, Popper H, Hoyer BH, London WT Ford EC, Bonino F, Purcell RH, Gerin JL. 1984. Transmission of the hepatitis B virus-associated delta agent to the eastern woodchuck. Proc Natl Acad Sci 81: 2208 2212.

Radjef N, Gordien E, Ivaniushina V, Gault E, Anais P, Drugan T, Trinchet JC, Roulot D, Tamby M, Milinkovitch MC, et al. 2004. Molecular phylogenetic analyses indicate a wide and ancient radiation of African hepatitis delta virus, suggesting a Deltavirus genus of at least seven major clades. J Virol 78: 2537-2544.

Reid CE, Lazinski DW. 2000. A host-specific function is required for ligation of a wide variety of ribozyme-processed RNAs. Proc Natl Acad Sci 97: 424-429.

Riccitelli NJ, Luptak A. 2013. HDV family of self-cleaving ribozymes. Prog Mol Biol Transl Sci 120: 1234-1171.

Rizzetto M, Canese MG, Arico J, Crivelli O, Bonino F, Trepo CG, Verme G. 1977. Immunofluorescence detection of a new antigen-antibody system associated to the hepatitis $B$ virus in the liver and in the serum of HBsAg carriers. Gut 18: 997-1003.

Rizzetto M, Canese MG, Gerin JL, London WT, Sly DL, Purcell RH. 1980a. Transmission of the hepatitis B virus-associated delta antigen to chimpanzees. J Infect Dis 141: 590-602.

Rizzetto M, Hoyer B, Canese MG, Shih JWK, Purcell RH Gerin JL. 1980b. $\delta$ Agent: Association of $\delta$ antigen with hepatitis B surface antigen and RNA in serum of $\delta$-infected chimpanzees. Proc Natl Acad Sci 77: 6124-6128.

Rocheleau L, Pelchat M. 2006. The subviral RNA database: A toolbox for viroids, the hepatitis delta virus and satellite RNAs research. BMC Microbiol 6: 24.

Rozzelle J, Wang J-G, Wagner D, Erickson B, Lemon S. 1995. Self-association of a synthetic peptide from the $\mathrm{N}$ terminus of the hepatitis delta virus protein into an immunoreactive $\alpha$-helical multimer. Proc Natl Acad Sci 92: 382386.

Ruminski DJ, Webb CH, Riccitelli NJ, Luptak A. 2011. Processing and translation initiation of non-long terminal repeat retrotransposons by hepatitis delta virus (HDV)like self-cleaving ribozymes. J Biol Chem 286: 4128641295.

Ryu WS, Netter HJ, Bayer M, Taylor J. 1993. Ribonucleoprotein complexes of hepatitis delta virus. J Virol 67: 3281-3287.

Salehi-Ashtiani K, Luptak A, Litovchick A, Szostak JW. 2006 A genomewide search for ribozymes reveals an HDV-like sequence in the human $C P E B 3$ gene. Science 313: 17881792.

Sebti SM, Hamilton AD. 2000. Farnesyltransferase and geranylgeranyltransferase I inhibitors and cancer therapy: Lessons from mechanism and bench-to-bedside translational studies. Oncogene 19: 6584-6593.

Seitz S, Urban S, Antoni C, Bottcher B. 2007. Cryo-electron microscopy of hepatitis $B$ virions reveals variability in envelope capsid interactions. EMBO J 26: 4160-4167.

Sharmeen L, Kuo MY, Dinter-Gottlieb G, Taylor J. 1988. Antigenomic RNA of human hepatitis delta virus can undergo self-cleavage. J Virol 62: 2674-2679.
Sharmeen L, Kuo MY, Taylor J. 1989. Self-ligating RNA sequences on the antigenome of human hepatitis delta virus. J Virol 63: 1428-1430.

Sureau C, Taylor J, Chao M, Eichberg J, Lanford R. 1989. A cloned DNA copy of hepatitis delta virus is infectious in the chimpanzee. J Virol 63: 4292-4297.

Sureau C, Guerra B, Lanford RE. 1993. Role of the large hepatitis B virus envelope protein in infectivity of the hepatitis delta virion. J Virol 67: 366-372.

Symons RH. 1994. Ribozymes. Curr Opin Struct Biol 4: 322 330.

Symons RH, Randles JW, ed. 1999. Encapsidated circular viroid-like satellite RNAs (virusoids) of plants. Springer, Berlin.

Taylor J. 1990. Hepatitis delta virus: cis and trans functions needed for replication. Cell 61: 371-373.

Taylor JM. 1999. Replication of human hepatitis delta virus: Influence of studies on subviral plant pathogens. Adv Vir Res 54: 45-60.

Taylor JM. 2014. Host RNA circles and the origin of hepatitis delta virus. World J Gastroenterol 20: 2971-2978.

Taylor J, Pelchat M. 2010. Origin of hepatitis $\delta$ virus. Fut Microbiol 5: 393-402.

Taylor JM, Purcell RH, Farci P. 2013. Hepatitis D ( $\delta$ ) virus. In Fields virology (ed. Knipe DM, Howley PM), pp. 2222 2241. Lippincott Williams \& Wilkins, Philadelphia.

Tseng CH, Lai MM. 2009. Hepatitis delta virus RNA replication. Viruses 1: 818-831.

Tseng CH, Cheng TS, Shu CY, Jeng KS, Lai MM. 2010. Modification of small hepatitis delta virus antigen by SUMO protein. J Virol 84: 918-927.

Wang K-S, Choo Q-L, Weiner AJ, Ou J-H, Najarian C, Thayer RM, Mullenbach GT, Denniston KJ, Gerin JL, Houghton M. 1986. Structure, sequence and expression of the hepatitis delta viral genome. Nature 323: 508-513.

Webb C-HT, Riccitelli NJ, Ruminski DJ, Luptak A. 2009. Widespread occurrence of self-cleaving ribozymes. Science 326: 953.

Wong SK, Lazinski DW. 2002. Replicating hepatitis delta virus RNA is edited in the nucleus by the small form of ADAR1. Proc Natl Acad Sci 99: 15118-15123.

Wu JC, Chiang TY, Shiue WK, Wang SY, Sheen IJ, Huang YH, Syu WJ. 1999. Recombination of hepatitis D virus RNA sequences and its implications. Mol Biol Evol 16: $1622-1632$.

Yamaguchi Y, Filipovska J, Yano K, Furuya A, Inukai N, Narita T, Wada T, Sugimoto S, Konarska MM, Handa H. 2001. Stimulation of RNA polymerase II elongation by hepatitis delta antigen. Science 293: 124-127.

Yamaguchi Y, Mura T, Chanarat S, Okamoto S, Handa H. 2007. Hepatitis delta antigen binds to the clamp of RNA polymerase II and affects transcriptional fidelity. Genes Cells 12: 863-875.

Yan H, Zhong G, Xu G, He W, Jing Z, Gao Z, Huang Y, Qi Y, Peng B, Wang H, et al. 2012. Sodium taurocholate cotransporting polypeptide is a functional receptor for human hepatitis B and D virus. eLife 1: e00049.

Zuccola HJ, Rozzelle JE, Lemon SM, Erickson BW, Hogle JM. 1998. Structural basis of the oligomerization of hepatitis delta antigen. Structure 6: 821-830. 


\section{$\&_{\mathrm{CSH}}^{\infty} \&$ Cold Spring Harbor

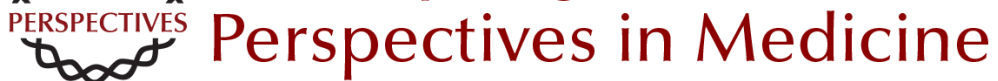

\section{Hepatitis D Virus Replication}

John M. Taylor

Cold Spring Harb Perspect Med 2015; doi: 10.1101/cshperspect.a021568

Subject Collection The Hepatitis B and Delta Viruses

Hepatitis B Virus X and Regulation of Viral Gene Expression

Betty L. Slagle and Michael J. Bouchard

The Woodchuck, a Nonprimate Model for Immunopathogenesis and Therapeutic Immunomodulation in Chronic Hepatitis B Virus Infection

Michael Roggendorf, Anna D. Kosinska, Jia Liu, et al.

Mouse Models of Hepatitis B Virus Pathogenesis Matteo lannacone and Luca G. Guidotti

Therapy of Delta Hepatitis

Cihan Yurdaydin and Ramazan Idilman

Immune Response in Hepatitis B Virus Infection Anthony Tan, Sarene Koh and Antonio Bertoletti

Hepatitis D Virus: Introduction and Epidemiology Mario Rizzetto

Management of Chronic Hepatitis B in Patients from Special Populations

Ching-Lung Lai and Man-Fung Yuen

Hepatitis B Virus Genotypes and Variants

Chih-Lin Lin and Jia-Horng Kao
Origins and Evolution of Hepatitis B Virus and Hepatitis D Virus

Margaret Littlejohn, Stephen Locarnini and Lilly Yuen

Assembly and Release of Hepatitis B Virus Lisa Selzer and Adam Zlotnick

Hepatitis D Virus Replication John M. Taylor

Treatment of Liver Cancer

Chun-Yu Liu, Kuen-Feng Chen and Pei-Jer Chen

Hepatitis B Virus and Hepatitis D Virus Entry, Species Specificity, and Tissue Tropism

Koichi Watashi and Takaji Wakita

Hepadnavirus Genome Replication and

Persistence Jianming Hu and Christoph Seeger

The Chimpanzee Model for Hepatitis B Virus Infection

Stefan F. Wieland

Hepatitis B Virus Epidemiology

Jennifer H. MacLachlan and Benjamin C. Cowie

For additional articles in this collection, see http://perspectivesinmedicine.cshlp.org/cgi/collection/ 